\title{
Contrasting Effects of Increased and Decreased Dopamine Transmission on Latent Inhibition in Ovariectomized Rats and Their Modulation by 17 $\beta$-Estradiol: An Animal Model of Menopausal Psychosis?
}

\author{
Michal Arad ${ }^{*,}$ ' and Ina Weiner' \\ 'Department of Psychology, Tel-Aviv University, Tel-Aviv, Israel
}

\begin{abstract}
Women with schizophrenia have later onset and better response to antipsychotic drugs (APDs) than men during reproductive years, but the menopausal period is associated with increased symptom severity and reduced treatment response. Estrogen replacement therapy has been suggested as beneficial but clinical data are inconsistent. Latent inhibition (LI), the capacity to ignore irrelevant stimuli, is a measure of selective attention that is disrupted in acute schizophrenia patients and in rats and humans treated with the psychosisinducing drug amphetamine and can be reversed by typical and atypical APDs. Here we used amphetamine (I mg/kg)-induced disrupted $\mathrm{LI}$ in ovariectomized rats to model low levels of estrogen along with hyperfunction of the dopaminergic system that may be occurring in menopausal psychosis, and tested the efficacy of APDs and estrogen in reversing disrupted LI. I $7 \beta$-Estradiol (50, I50 $\mu \mathrm{g} / \mathrm{kg})$, clozapine (atypical APD; $5,10 \mathrm{mg} / \mathrm{kg}$ ), and haloperidol (typical APD; $0.1,0.3 \mathrm{mg} / \mathrm{kg}$ ) effectively reversed amphetamine-induced LI disruption in sham rats, but were much less effective in ovariectomized rats; 17 $\beta$-estradiol and clozapine were effective only at high doses (I50 $\mu \mathrm{g} / \mathrm{kg}$ and $10 \mathrm{mg} / \mathrm{kg}$, respectively), whereas haloperidol failed at both doses. Haloperidol and clozapine regained efficacy if coadministered with $17 \beta$-estradiol $(50 \mu \mathrm{g} / \mathrm{kg}$, an ineffective dose). Reduced sensitivity to dopamine (DA) blockade coupled with spared/potentiated sensitivity to DA stimulation after ovariectomy may provide a novel model recapitulating the combination of increased vulnerability to psychosis with reduced response to APD treatment in female patients during menopause. In addition, our data show that 17 $\beta$-estradiol exerts antipsychotic activity.

Neuropsychopharmacology (2010) 35, 1570-1582; doi:I0.1038/npp.2010.28; published online 17 March 2010
\end{abstract}

Keywords: amphetamine; antipsychotic drugs; estrogen; latent inhibition; menopausal psychosis; schizophrenia

\section{INTRODUCTION}

Since description of schizophrenia as 'men illness' by Kraepeline (1919), scores of epidemiological and clinical studies have documented gender differences in schizophrenia. Women have a more favorable illness course during the reproductive years, characterized by later onset of symptoms, lower symptom severity, and better response to antipsychotic drug (APD) treatment (Agius et al, 2009; Angermeyer and Kuhn, 1988; Hafner, 2003; Hafner et al, 1989; Iacono and Beiser, 1992; Lindamer et al, 1997; Mortimer, 2007; Pregelj, 2009; Riecher-Rossler and Hafner, 2000; Salem and Kring, 1998; Seeman, 1982, 1986; Szymanski et al, 1995; Tamminga, 1997). In contrast,

* Correspondence: M Arad, Department of Psychology, Tel-Aviv University, Ramat-Aviv 39040, Tel-Aviv 69978, Israel, Tel: +972 3640 9543, Fax: + 9723640 9547, E-mail: aradmich@post.tau.ac.il Received 3 January 2010; revised I5 February 2010; accepted 16 February 2010 menopause is associated with increased vulnerability to illness, elevated symptom severity, and reduced response to treatment (Horacek et al, 2006; Kulkarni et al, 1996, 2008b; Lane et al, 1999; Salokangas, 1995; Saugstad, 1989; Seeman and Lang, 1990). Increased symptom severity and reduced treatment response are associated also with low-estrogen phases of the menstrual cycle (Ereshefsky et al, 1991; Farina et al, 1981; Lane et al, 1999; Salokangas, 1995; Seeman, 1989; Simpson et al, 1990; Tamminga, 1997). These data have been captured in the estrogen hypothesis of schizophrenia that posits exacerbations of illness manifestations in women are related to low levels of estrogen (Hafner et al, 1989; Huber et al, 2004; Seeman and Lang, 1990). Accordingly, it has been suggested that exogenous estrogen on its own or combined with APDs may have therapeutic potential in schizophrenia, although this notion has been challenged (for recent reviews see Agius et al, 2009; Mortimer, 2007).

Ovariectomy (OVX)-induced hormonal decline in rats is considered to model decreased gonadal function during 
menopause (Adam et al, 2009; Daniel et al, 2006; Gurkan et al, 1986; LeBlanc et al, 2009; Rogers et al, 2009; Walf et al, 2009), and has been proposed specifically to model the hormonal state associated with predisposition to schizophrenia during menopause (Bosse and Di Paolo, 1995). Although many studies showed that OVX is associated with poorer behavioral and cognitive performance, including tasks considered relevant to schizophrenia such as social interaction and object recognition (Barnes et al, 2006; Frye, 2001; Frye et al, 2006b, 2007; Frye and Rhodes, 2006a; Paris and Frye, 2008), the study of the estrogen hypothesis using animal models of schizophrenia has been limited. Some support derives from studies showing that estrogen affects prepulse inhibition (PPI) (Gogos et al, 2009; Gogos and Van den Buuse, 2004; Koch, 1998; Vaillancourt et al, 2002; Van den Buuse and Eikelis, 2001), a measure of sensorimotor gating whose disruption is considered to model sensorimotor deficits in schizophrenia, as well as the response to the pro-psychotic drugs amphetamine and cocaine (Becker and Beer, 1986; Becker and Rudick, 1999; Earley and Leonard, 1978; Gibbs et al, 1998; Naik et al, 1978; Segarra et al, 2009).

We have recently tested the estrogen hypothesis using the latent inhibition (LI) model of schizophrenia (Arad and Weiner, 2008, 2009). LI is a cross-species selective attention phenomenon manifested as retarded conditioning to a stimulus that was pre-exposed (PE) without consequence before conditioning, and is commonly considered to index the ability to ignore irrelevant stimuli. Loss of LI induced in the rat by the psychotomimetic dopamine (DA) releaser amphetamine and its reversal by APDs is a well-established model of positive symptoms of schizophrenia (Lipska and Weinberger, 2002; Moser et al, 2000; Weiner, 2003; Weiner and Arad, 2009). We (Arad and Weiner, 2009) have shown that hormonal cessation after OVX led to loss of LI, which was restored after the administration of $17 \beta$ estradiol. Most interestingly, we found that OVX interfered with the efficacy of the typical APD haloperidol to restore LI, mimicking the reduced sensitivity to APD treatment seen in schizophrenic women during menopause. Furthermore, haloperidol regained efficacy when coadministered with a behaviorally inactive dose of $17 \beta$ estradiol, indirectly supporting an antipsychotic action of $17 \beta$-estradiol.

Here we sought to expand the OVX/LI model by testing the efficacy of $17 \beta$-estradiol, haloperidol, and clozapine to reverse amphetamine-induced disruption of LI in OVX rats. Given our previous finding that OVX reduced the efficacy of APDs, one major question of interest here was whether OVX would also reduce the efficacy of amphetamine. We hypothesized that amphetamine would not lose its efficacy to disrupt LI in OVX compared to sham rats. Conversely, APDs would be less effective in reversing amphetamineinduced LI disruption in OVX rats, but their action would be potentiated by concurrent $17 \beta$-estradiol treatment, which would also block amphetamine effect on its own. These outcomes would capture the combination of increased vulnerability to psychosis with reduced response to APD treatment that may be occurring during menopause in women vulnerable to psychosis, and support a direct antipsychotic (anti-amphetamine) action of $17 \beta$ estradiol.

\section{MATERIALS AND METHODS}

\section{Animals}

Female Wistar rats bred in our laboratory were housed 3-4 per cage under reversed cycle lighting (lights on 0700-1900 hours) with ad lib access to food and water. They were about 7 weeks old and weighing 155-267 g when submitted to OVX and approximately 3 months old and weighing 248-469 g when behavioral testing begun. All experimental protocols conformed to the guidelines of the Institutional Animal Care and Use Committee of Tel Aviv University, Israel, and to the guidelines of the NIH (animal welfare assurance number A5010-01, expires on 30 September 2011). All efforts were made to minimize the number of animals used and their suffering.

\section{Ovariectomy}

Rats were bilaterally ovariectomized under isoflurane (Nicholas Piramal, UK) anesthesia. After shaving the abdominal area, we made a midline incision through the skin and muscle layer. Fallopian tubes were ligated by a nylon thread, after which the ovaries were carefully removed. Sutures of muscle layer and skin were removed 10 days later. Rats were allowed additional 3 weeks of recovery after removal of the sutures, before the beginning of water restriction (see below). Within the 3-week recovery period, about a week after removal of sutures, vaginal smears were collected daily in the morning for 8 days in sham and OVX rats to confirm regular or discontinuation of estrous cycle. Phases of the estrous cycle were determined by the morphology of cells in the vaginal smear under a light microscope (Marcondes et al, 2002). Sham-operated controls underwent an identical surgical procedure without ovaries' removal. Only sham females with regular 4-day cycles in succession and OVX rats without estrous cycle were used for behavioral testing.

\section{Latent Inhibition}

LI was measured in a thirst-motivated conditioned emotional response procedure as described previously (Arad and Weiner, 2009). Water-restricted $(23 \mathrm{~h})$ rats were trained to drink in the experimental chambers for 15-20 min per day for 5 days. Water in the chambers was given in addition to the $1 \mathrm{~h}$ water in home cages. The LI procedure consisted of four stages given $24 \mathrm{~h}$ apart. Pre-exposure: with the bottle removed, $P E$ rats received 40 or 50 tones $(10 \mathrm{~s}, 80 \mathrm{~dB}$, $2.8 \mathrm{kHz}) 40 \mathrm{~s}$ apart, whereas non-pre-exposed (NPE) rats were confined to the chamber. Conditioning: with the bottle removed, all rats received one or two tone-shock (tone: $10 \mathrm{~s}$, $80 \mathrm{~dB}, 2.8 \mathrm{kHz}$; shock: $1 \mathrm{~s}, 0.5 \mathrm{~mA}$ ) pairings given $5 \mathrm{~min}$ apart. Lick retraining: rats were given a 15 min drinking session as in initial training. Data of rats that failed to complete 600 licks were dropped from the analysis. Test: rats were placed in the chambers with access to the bottle. When the rat completed 75 licks, the tone was presented for 5 min. Times to complete 25 licks before and after tone onset were recorded. Times to complete licks $76-100$ were submitted to logarithmic transformation to allow parametric analysis of variance (ANOVA). Longer log times indicate stronger suppression of drinking. LI is defined as 
shorter times to complete licks $76-100$ after tone onset (weaker fear conditioning) of the PE compared to NPE rats.

\section{Drug and Hormone Administration}

Amphetamine and APDs were administered intraperitoneally and $17 \beta$-estradiol was administered subcutaneously, all in a volume of $1 \mathrm{ml} / \mathrm{kg}, 30$ (amphetamine and clozapine), 60 (haloperidol), or 120 (17 $\beta$-estradiol) $\mathrm{min}$ before preexposure and conditioning stages. Amphetamine (Sigma, Israel) was dissolved in saline and administered at a dose of $1 \mathrm{mg} / \mathrm{kg}$. Haloperidol (Johnson\&Johnson, Belgium) was prepared from an ampoule containing $5 \mathrm{mg}$ haloperidol in $1 \mathrm{ml}$ solvent containing $6 \mathrm{mg}$ lactic acid, diluted with saline, and administered at doses of 0.1 or $0.3 \mathrm{mg} / \mathrm{kg}$. Clozapine (Novartis, Switzerland) was dissolved in $1 \mathrm{~N}$ acetic acid $(1.5 \mathrm{ml} / 10 \mathrm{mg})$, diluted with saline, and administered at doses of 5 or $10 \mathrm{mg} / \mathrm{kg}$. The doses of haloperidol and clozapine are routinely used in our LI studies (Arad and Weiner, 2009; Weiner et al, 1996b). 17 $\beta$-Estradiol (Sigma) was dissolved in corn oil and administered at doses of 10 , 50 , and $150 \mu \mathrm{g} / \mathrm{kg}$. These doses were chosen on the basis of behavioral literature and used in our previous study in OVX rats (Arad and Weiner, 2009; Galea et al, 2001; Gibbs et al, 1998; Nofrey et al, 2008; Van den Buuse and Eikelis, 2001; Walf and Frye, 2010). No-drug controls received the corresponding vehicle/s as follows: saline as amphetamine vehicle, saline solution containing $1 \%$ of lactic acid as haloperidol vehicle, saline solution containing $7.5 \%$ acetic acid as clozapine vehicle, and oil as $17 \beta$-estradiol vehicle. In all experiments, lick retraining and test sessions were conducted in a drug-free state.

\section{Assessment of Estradiol Serum Levels}

Serum estradiol levels produced by the four $17 \beta$-estradiol conditions were determined in separate groups of sham and OVX rats ( $n$ per group 7-8). Rats were given two injections $24 \mathrm{~h}$ apart (mimicking the injection protocol of LI).

Blood was taken by cardiac puncture $(1 \mathrm{ml}$, without preservative). The blood was allowed to clot for 20-40 min and was centrifuged at $930 \mathrm{~g}$ (2000 r.p.m.) for $20 \mathrm{~min}$. Afterward serum was collected and was assayed immediately.

$17 \beta$-Estradiol serum levels were measured using an enzyme-linked immunosorbent assay kits (Cayman, Michigan, USA), based on manufacturer's instructions. Table 1 presents mean serum levels of estradiol following our administration regime in comparison to levels reported for different stages of the estrous cycle and pregnancy (Nequin et al, 1979; Shaikh, 1971).

\section{Experimental Design}

Experiment 1. In our previous study we showed that LI was absent in OVX rats (Arad and Weiner, 2009). Because here we intended to test whether amphetamine disrupts LI in OVX rats, we needed to create conditions under which OVX no longer disrupts LI, so that the effect of amphetamine could be manifested. As detailed by us elsewhere (Weiner, 1990, 2003; Weiner and Arad, 2009), the expression of LI is a function of the balance between the strength of preexposure and the strength of conditioning, so that increasing the strength of pre-exposure (eg, by increasing the number of stimulus pre-exposures) and/or decreasing the strength of conditioning (eg, by reducing the number of conditioning trials) are expected to promote the expression of LI. The aim of experiment 1 was to test whether such manipulations of pre-exposure and conditioning parameters would restore LI in OVX rats. In our previous study, OVX-induced disruption of LI was obtained using 40 pre-exposures and 2 conditioning trials. Here, we either increased the number of pre-exposures from 40 to 50 while keeping 2 conditioning trials or reduced the number of conditioning trials from 2 to 1 while keeping 40 preexposures, and compared LI under these two combinations to the previous combination of 40 pre-exposures and 2 conditioning trials. The experiment included 36 OVX rats divided into six experimental groups ( $n$ per group 6 ) in a $2 \times 3$ design with main factors of pre-exposure (NPE, PE) and pre-exposure-conditioning combination (40 pre-exposures and 1 conditioning trial; 40 pre-exposures and 2 conditioning trials; 50 pre-exposures and 2 conditioning trials). The latter combination that yielded LI in OVX rats was used in experiments 2-7.

Experiment 2 tested the capacity of amphetamine to disrupt LI in OVX rats. The experiment included 62 rats (32 sham, 30 OVX) divided into eight experimental groups ( $n$ per group 6-8) in a $2 \times 2 \times 2$ design with main factors of pre-exposure $(0,50)$, gonadal status (sham, OVX), and treatment $(0,1 \mathrm{mg} / \mathrm{kg}$ amphetamine).

Experiment 3 tested the capacity of $17 \beta$-estradiol to reverse amphetamine-induced LI disruption in OVX rats. The experiment included 236 rats (119 sham, 117 OVX) divided into 32 experimental groups ( $n$ per group $6-8$ ) in a $2 \times 2 \times 2 \times 4$ design with main factors of pre-exposure

Table I Serum Levels of Estradiol in Sham and OVX Rats After Administration of 17 $\beta$-Estradiol at Three Doses

\begin{tabular}{|c|c|c|c|c|c|c|c|}
\hline \multirow[t]{2}{*}{ Gonads } & \multicolumn{7}{|c|}{ E state } \\
\hline & Control & $\begin{array}{c}\text { Low E } \\
(10 \mu g / k g)\end{array}$ & Metestrus & $\begin{array}{c}\text { Medium E } \\
(50 \mu \mathrm{g} / \mathrm{kg})\end{array}$ & Proestrus & $\begin{array}{c}\text { High E } \\
(150 \mu \mathrm{g} / \mathrm{kg})\end{array}$ & $\begin{array}{l}\text { Pregnancy } \\
\text { (GD 20-22) }\end{array}$ \\
\hline Sham & $48.7 \pm 12.7$ & $20.2 \pm 3.2$ & $20.6 \pm 1.6$ & $120.6 \pm 14.0$ & $142.2 \pm 45.8$ & $628.4 \pm 95.0$ & $628 \pm 210$ \\
\hline ovx & $5.5 \pm 0.6$ & $17.9 \pm 3.5$ & - & $125.8 \pm 15.7$ & - & $660.4 \pm 59.4$ & - \\
\hline
\end{tabular}

Mean ( \pm SEM) of serum level of estradiol $2 \mathrm{~h}$ after second injection (given $24 \mathrm{~h}$ apart) of $0,10,50$, or $150 \mu \mathrm{g} / \mathrm{kg}$ of $17 \beta$-estradiol, in sham and $\mathrm{OVX}$ rats.

For comparison, levels found by Nequin et al (1979) along the cycle (metestrus and proestrus) and by Shaikh (197I) on gestation days (GD) 20-22 are provided. 
$(0,50)$, gonadal status (sham, OVX), treatment $(0,1 \mathrm{mg} / \mathrm{kg}$ amphetamine), and pretreatment $(0,10,50$, or $150 \mu \mathrm{g} / \mathrm{kg}$ $17 \beta$-estradiol).

Experiments 4 and 5 tested the capacity of the typical and atypical APDs, haloperidol $(0.1,0.3 \mathrm{mg} / \mathrm{kg})$ and clozapine $(5,10 \mathrm{mg} / \mathrm{kg})$, respectively, to reverse amphetamine-induced LI disruption in OVX rats. Because it is well documented that haloperidol and clozapine at the doses and injection protocol used here do not affect LI (Weiner and Feldon, 1987; Weiner et al, 1997; Weiner et al, 1996b), we did not use separate control (sham and OVX) groups for each APD dose but instead injected each dose to half of the controls. Both experiments included 20 experimental groups ( $n$ per group $6-8$ ) in a $2 \times 2 \times 5$ design with main factors of pre-exposure $(0,50)$, gonadal status (sham, OVX), and treatment (vehicle, APD, amphetamine, amphetamine + low APD dose, amphetamine + high APD dose). Experiment 4 included 141 rats (71 sham, 70 OVX), whereas experiment 5 included 151 rats ( 77 sham, 74 OVX).

Experiments 6 and 7. Because amphetamine-induced disruption of LI in OVX rats was resistant to haloperidol (experiment 4) and showed reduced response to clozapine (experiment 5), here we tested whether the efficacy of haloperidol (0.1 mg/kg; experiment 6) and clozapine ( $5 \mathrm{mg} / \mathrm{kg}$; experiment 7) in reversing amphetamine-induced LI disruption would be restored by their coadministration with an ineffective dose of $17 \beta$-estradiol $(50 \mu \mathrm{g} / \mathrm{kg})$. The experiments included 115 and 116, respectively, OVX rats divided into 16 experimental groups ( $n$ per group 7-8) in a $2 \times 2 \times 4$ design with main factors of pre-exposure $(0,50)$, treatment (saline, amphetamine), and pretreatment (vehicle, APD, $17 \beta$-estradiol, APD $+17 \beta$-estradiol).

\section{Statistical Analysis}

Times to complete licks 51-75 (before tone onset) and logarithmically transformed mean times to complete licks 76-100 (after tone onset) were analyzed with two-way ANOVA with main factors of pre-exposure and gonadal status (experiment 1); three-way ANOVAs with main factors of pre-exposure, gonadal status, and treatment (experiment 2,4 , and 5) or pre-exposure, treatment, and pretreatment (experiment 6 and 7); and a four-way ANOVA with main factors of pre-exposure, gonadal status, treatment, and pretreatment (experiment 3). In cases of significant interactions involving the factor of pre-exposure, LSD post hoc comparisons were used to assess the difference between the PE and NPE groups within each treatment condition.

\section{RESULTS}

There were no differences between the experimental groups in the times to complete licks 51-75 (A period; all $p$ 's $>0.05$ ) in any of the seven experiments (overall mean A periods were $8.19,9.58,7.92,10.77,10.04,9.66$, and 7.13 for experiments $1-7$, respectively).

\section{Experiment 1: LI in OVX Rats}

Figure 1 presents the mean log times to complete licks 76-100 (after tone onset) of the PE and NPE OVX rats in the three experimental conditions. As shown by us previously,

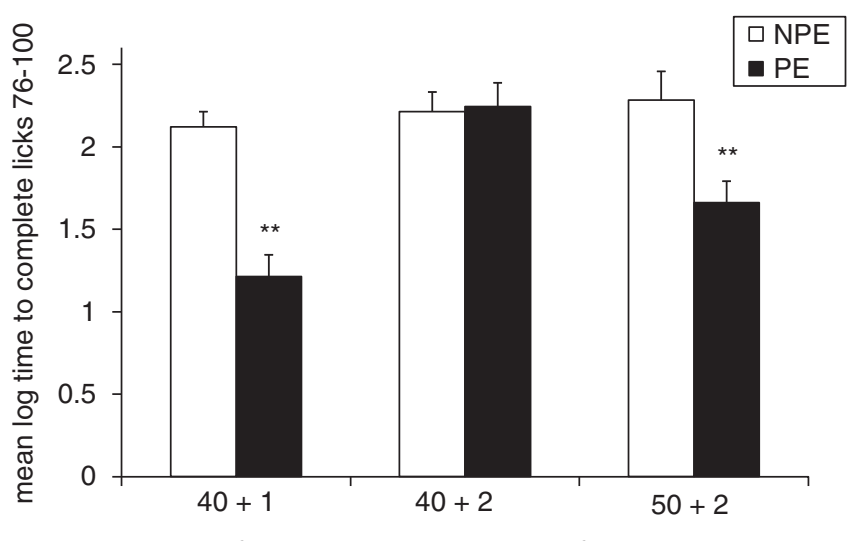

number of pre-exposures + number of conditioning trials

Figure I LI in OVX rats. Mean ( \pm SEM) log times to complete licks $76-$ 100 (after tone onset) of the pre-exposed (PE) and the non-pre-exposed (NPE) OVX rats in three pre-exposure/conditioning combinations (number of pre-exposures + number of conditioning trials): 40 preexposures and I conditioning trial $(40+1) ; 40$ pre-exposures and 2 conditioning trials $(40+2)$; and 50 pre-exposures and 2 conditioning trials $(50+2)$. Asterisks $(* *)$ indicate significant difference between the PE and NPE groups, namely, presence of $\mathrm{LI}(p<0.0 \mathrm{I})$.

when 40 pre-exposures were followed by 2 conditioning trials $(40+2)$, there was no difference in suppression between the PE and NPE groups, ie, no LI. In contrast, rats exhibited LI, ie, lower suppression of the $\mathrm{PE}$ as compared to the NPE group, when 40 pre-exposures were followed by 1 conditioning trial $(40+1)$ or when 50 preexposures were followed by 2 conditioning trials $(50+1)$. ANOVA yielded significant main effects of pre-exposure $\left(\mathrm{F}_{(1,30)}=20.88, \quad p<0.01\right)$ and pre-exposure/conditioning combination $\left(\mathrm{F}_{(2,30)}=8.85, p<0.01\right)$, as well as their interaction $\left(\mathrm{F}_{(2,30)}=6.45, p<0.01\right)$. Post hoc comparisons confirmed the presence of LI in the $40+1$ and $50+2$ conditions $(p<0.01)$, but not in the $40+2$ condition.

On the basis of these results in all the following experiments (2-7), we used 50 pre-exposures and 2 conditioning trials.

\section{Experiment 2: Effects of Amphetamine $(1 \mathrm{mg} / \mathrm{kg})$ on LI in Sham and OVX Rats}

Figure 2 presents the mean log times to complete licks 76-100 (after tone onset) of the PE and NPE sham and OVX rats injected with amphetamine $(0,1 \mathrm{mg} / \mathrm{kg})$. As can be seen, saline-injected sham and OVX rats exhibited LI, but LI was lost in both groups after amphetamine injection. ANOVA yielded a significant effect of pre-exposure $\left(\mathrm{F}_{(1,54)}=34.08, p<0.001\right)$ and a significant pre-exposure $\times$ treatment interaction $\left(\mathrm{F}_{(1,54)}=19.57, p<0.001\right)$. Post hoc comparisons confirmed the presence of LI in saline $(p<0.001)$, but not in amphetamine conditions.

\section{Experiment 3: Effects of $17 \beta$-Estradiol $(10,50$, or $150 \mu \mathrm{g} / \mathrm{kg}$ ) on Amphetamine-Induced LI Disruption in Sham and OVX Rats}

Figure 3 presents the mean log times to complete licks 76-100 (after tone onset) of the PE and NPE saline- or amphetamine-injected sham and OVX rats pretreated with 
$0,10,50$, or $150 \mu \mathrm{g} / \mathrm{kg}$ of $17 \beta$-estradiol. As can be seen, saline-injected sham and OVX rats exhibited LI whereas amphetamine-injected sham and OVX rats did not exhibit LI. LI was restored in amphetamine-injected sham rats given 50 or $150 \mu \mathrm{g} / \mathrm{kg}$ of $17 \beta$-estradiol, whereas in OVX rats only the high $17 \beta$-estradiol dose reversed amphetamineinduced disruption of LI. On its own, $17 \beta$-estradiol disrupted LI at the low dose of $10 \mu \mathrm{g} / \mathrm{kg}$ in both sham and OVX rats but spared LI at the two higher doses. ANOVA yielded main effects of pre-exposure $\left(\mathrm{F}_{(1,204)}=55.024\right.$,

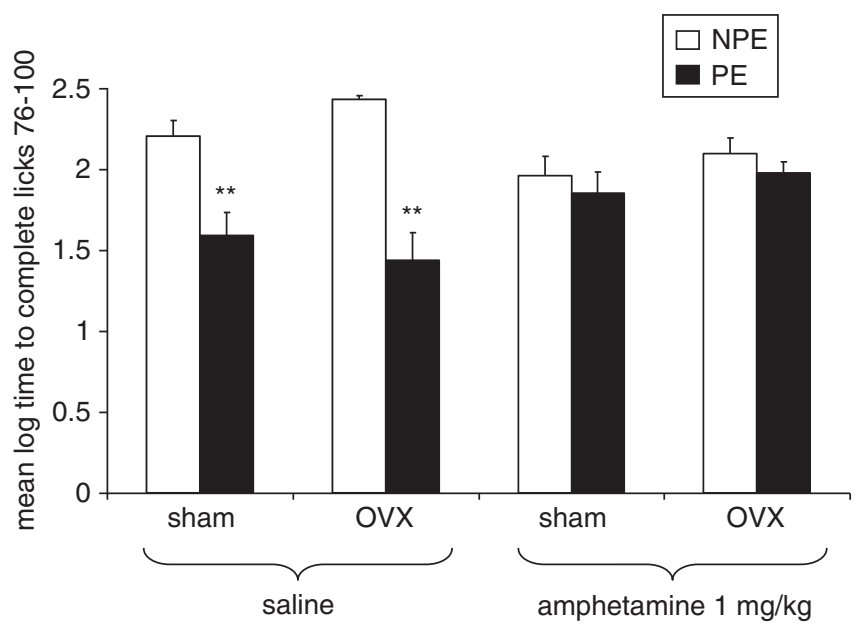

Figure 2 Effects of amphetamine (I mg/ $\mathrm{kg})$ on $\mathrm{LI}$ in sham and OVX rats. Mean ( \pm SEM) log times to complete licks 76-100 (after tone onset) of the pre-exposed (PE) and the non-pre-exposed (NPE) sham and OVX rats injected with saline or I $\mathrm{mg} / \mathrm{kg}$ amphetamine. Asterisks (**) indicate significant difference between the PE and NPE groups, namely, presence of LI $(p<0.01)$. $p<0.0001)$, treatment $\left(\mathrm{F}_{(1,204)}=11.296, p<0.001\right)$, and pretreatment $\left(\mathrm{F}_{(3,204)}=2.74, p<0.05\right)$, as well as a significant pre-exposure $\times$ gonadal status $\times$ treatment $\times$ pretreatment interaction $\left(\mathrm{F}_{(3,204)}=3.023, \quad p<0.05\right)$. Post hoc comparisons confirmed the presence of $\mathrm{LI}$ in saline-injected sham and OVX rats given 0,50 , or $150 \mu \mathrm{g} / \mathrm{kg} 17 \beta$-estradiol; in amphetamine-injected sham rats given 50 or $150 \mu \mathrm{g} / \mathrm{kg}$ $17 \beta$-estradiol; and in OVX rats given $150 \mu \mathrm{g} / \mathrm{kg} 17 \beta$ estradiol $(p$ 's $<0.05)$, but not in the other conditions.

\section{Experiment 4: Effects of Haloperidol $(0.1,0.3 \mathrm{mg} / \mathrm{kg}$ ) on Amphetamine-Induced LI Disruption in Sham and OVX Rats}

Figure 4 presents the mean log times to complete licks 76-100 (after tone onset) of the PE and NPE saline- or amphetamine-injected sham and OVX rats pretreated with $0,0.1$, or $0.3 \mathrm{mg} / \mathrm{kg}$ of haloperidol. As can be seen, salineinjected sham and OVX rats exhibited LI whereas amphetamine-injected sham and OVX rats did not exhibit LI. LI was restored in amphetamine-injected sham rats given both doses of haloperidol, whereas both doses were ineffective in amphetamine-injected OVX rats. On its own, haloperidol spared LI. ANOVA yielded significant main effects of pre-exposure $\left(\mathrm{F}_{(1,121)}=119.42, p<0.001\right)$, gonadal status $\left(\mathrm{F}_{(1,121)}=5.32, \quad p<0.05\right)$, and treatment $\left(\mathrm{F}_{(4,121)}=4.99\right.$, $p<0.05)$, as well as a significant pre-exposure $\times$ gonadal status $\times$ treatment interaction $\left(\mathrm{F}_{(4,121)}=2.75, \quad p<0.05\right)$. Post hoc comparisons confirmed the presence of LI in saline-injected sham and OVX rats that received vehicle or haloperidol and in amphetamine-injected sham rats that received both doses of haloperidol $(p$ 's $<0.01)$, but not in the other conditions.

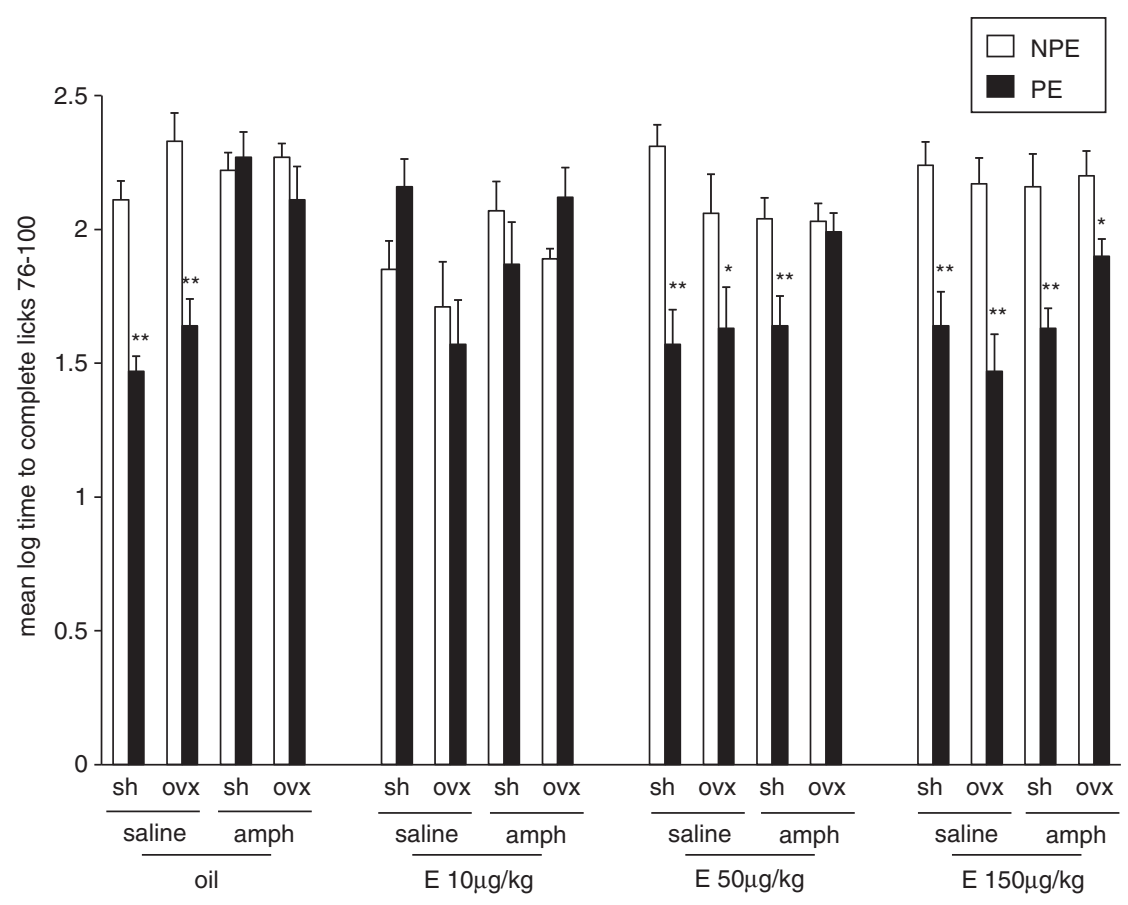

Figure 3 Effects of $17 \beta$-estradiol $(10,50$, or $150 \mu \mathrm{g} / \mathrm{kg}$ ) on amphetamine-induced LI disruption in sham and OVX rats. Mean ( \pm SEM) log times to complete licks 76-100 (after tone onset) of the pre-exposed (PE) and the non-pre-exposed (NPE) saline- or amphetamine (amph)-injected sham (sh) and OVX (ovx) females, administered with $0,10,50$, or $150 \mu \mathrm{g} / \mathrm{kg}$ of I $17 \beta$-estradiol (oil, E I0 $\mu \mathrm{g} / \mathrm{kg}$, E $50 \mu \mathrm{g} / \mathrm{kg}$, or E I $50 \mu \mathrm{g} / \mathrm{kg}$, respectively). Asterisks indicate a significant difference between the PE and NPE groups, namely, presence of $\mathrm{LI}(* p<0.05$; $* * 0<0.0 \mathrm{I})$. 


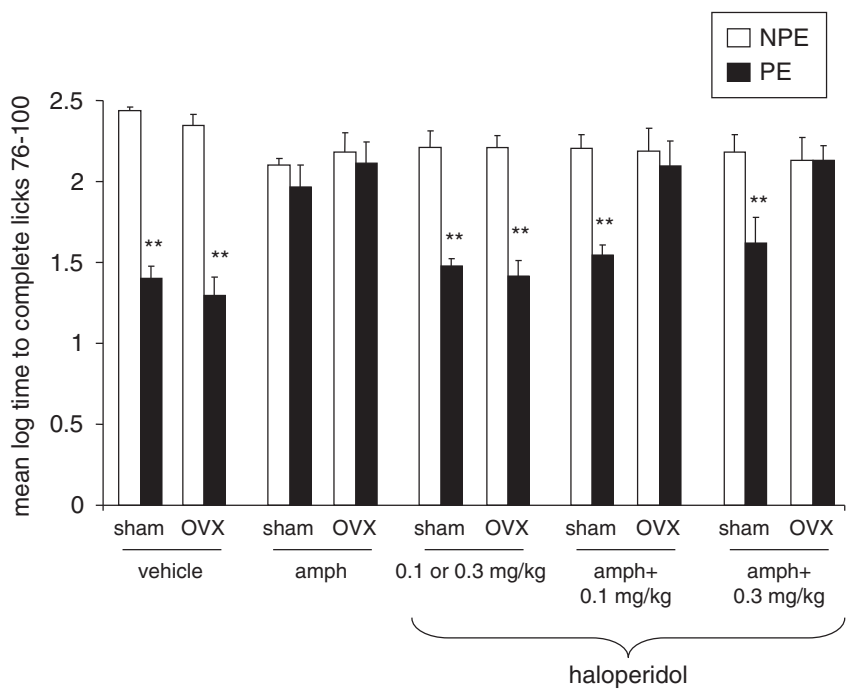

Figure 4 Effects of haloperidol $(0.1,0.3 \mathrm{mg} / \mathrm{kg})$ on amphetamineinduced $\mathrm{LI}$ disruption in sham and OVX rats. Mean $( \pm$ SEM) log times to complete licks 76-100 (after tone onset) of the pre-exposed (PE) and the non-pre-exposed (NPE) saline- or amphetamine (amph)-injected sham and OVX rats that received haloperidol ( 0.1 or $0.3 \mathrm{mg} / \mathrm{kg}$ to half of the group), amphetamine $+0.1 \mathrm{mg} / \mathrm{kg}$ haloperidol, or amphetamine $+0.3 \mathrm{mg} / \mathrm{kg}$ haloperidol. Asterisks (**) indicate significant difference between the PE and NPE groups, namely, presence of $\mathrm{LI}(p<0.0 \mathrm{I})$.

Experiment 5: Effects of Clozapine $(5,10 \mathrm{mg} / \mathrm{kg})$ on Amphetamine-Induced LI Disruption in Sham and OVX Rats

Figure 5 presents the mean log times to complete licks 76-100 (after tone onset) of the PE and NPE saline- or amphetamine-injected sham and OVX rats pretreated with 0,5 , or $10 \mathrm{mg} / \mathrm{kg}$ of clozapine. As can be seen, salineinjected sham and OVX rats exhibited LI whereas amphetamine-injected sham and OVX rats did not exhibit LI. LI was restored in amphetamine-injected sham rats given both doses of clozapine, whereas only the high dose was effective in amphetamine-injected OVX rats. On its own, clozapine spared LI.

ANOVA yielded significant main effects of pre-exposure $\left(\mathrm{F}_{(1,131)}=143.36, p<0.001\right)$, gonadal status $\left(\mathrm{F}_{(1,131)}=3.96\right.$, $p<0.05)$, and treatment $\left(\mathrm{F}_{(4,131)}=13.84, p<0.001\right)$, as well as a significant pre-exposure $\times$ gonadal status $\times$ treatment interaction $\left(\mathrm{F}_{(4,131)}=2.93, p<0.05\right)$. Post hoc comparisons confirmed the presence of LI in saline-injected sham and OVX rats that received vehicle or clozapine, in amphetamine-injected sham rats that received both doses of clozapine, and in amphetamine-injected OVX rats that received the high dose of clozapine $(p$ 's $<0.01)$, but not in the other conditions.

\section{Experiment 6: Effects of Coadministration of} Haloperidol $(0.1 \mathrm{mg} / \mathrm{kg})$ and $17 \beta$-Estradiol $(50 \mu \mathrm{g} / \mathrm{kg})$ on Amphetamine-Induced LI Disruption in OVX Rats

Figure 6 presents the mean log times to complete licks 76-100 (after tone onset) of the PE and NPE saline- or amphetamine-injected OVX rats pretreated with vehicle, $0.1 \mathrm{mg} / \mathrm{kg}$ haloperidol, $50 \mu \mathrm{g} / \mathrm{kg} 17 \beta$-estradiol or haloperidol

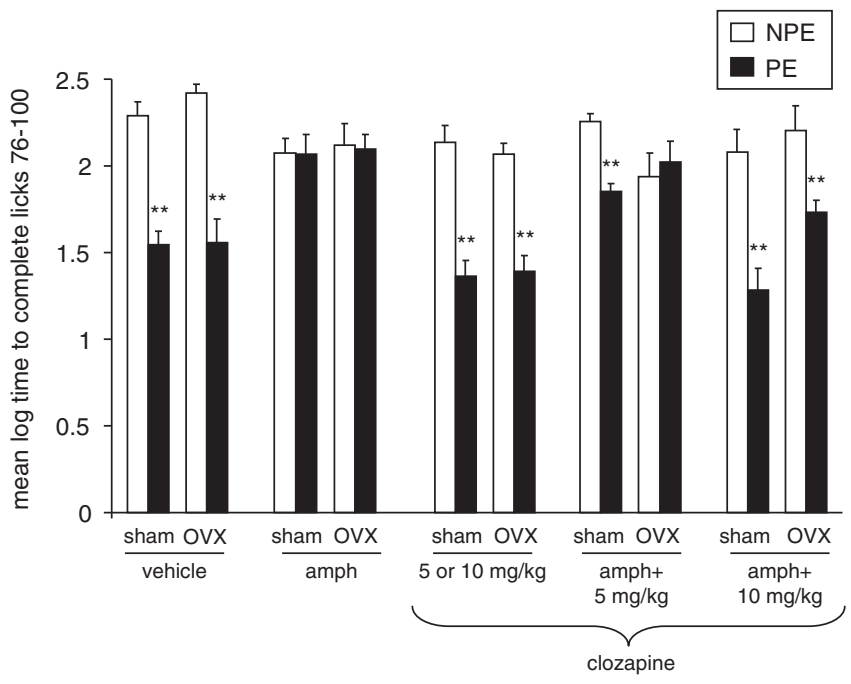

Figure 5 Effects of clozapine $(5,10 \mathrm{mg} / \mathrm{kg})$ on amphetamine-induced LI disruption in sham and OVX rats. Mean ( \pm SEM) log times to complete licks 76-100 (after tone onset) of the pre-exposed (PE) and the non-preexposed (NPE) saline- or amphetamine (amph)-injected sham and OVX rats that received clozapine (5 or $10 \mathrm{mg} / \mathrm{kg}$ to half of the group), amphetamine $+5 \mathrm{mg} / \mathrm{kg}$ clozapine, or amphetamine $+10 \mathrm{mg} / \mathrm{kg}$ clozapine. Asterisks (**) indicate significant difference between the PE and NPE groups, namely, presence of $\mathrm{LI}(p<0.0 \mathrm{I})$.

$+17 \beta$-estradiol. As can be seen, vehicle-injected OVX rats exhibited LI whereas amphetamine-injected OVX rats did not exhibit LI. Administration of haloperidol or $17 \beta$-estradiol alone failed to restore LI in amphetamineinjected OVX rats, but LI was restored in rats that were coadministered with haloperidol and $17 \beta$-estradiol. On their own, haloperidol and $17 \beta$-estradiol spared LI. ANOVA yielded significant main effects of pre-exposure $\left(\mathrm{F}_{(1,99)}=126.53, p<0.001\right)$ and treatment $\left(\mathrm{F}_{(1,99)}=26.45\right.$, $p<0.001)$, as well as a significant pre-exposure $\times$ treatment $\times$ pretreatment interaction $\quad\left(\mathrm{F}_{(3,99)}=9.39\right.$, $p<0.001)$. Post hoc comparisons confirmed the presence of LI in all four groups of saline-injected OVX rats, as well as in amphetamine-injected rats that received haloperidol $+17 \beta$-estradiol ( $p$ 's $<0.01$ ), but not in the other conditions.

\section{Experiment 7: Effects of Coadministration of Clozapine} $(5 \mathrm{mg} / \mathrm{kg})$ and $17 \beta$-Estradiol $(50 \mu \mathrm{g} / \mathrm{kg})$ on Amphetamine-Induced LI Disruption in OVX Rats

Figure 7 presents the mean log times to complete licks 76-100 (after tone onset) of the PE and NPE saline- or amphetamine-injected OVX rats pretreated with vehicle, $5 \mathrm{mg} / \mathrm{kg}$ clozapine, $50 \mu \mathrm{g} / \mathrm{kg} 17 \beta$-estradiol or clozapine + $17 \beta$-estradiol. As can be seen, vehicle-injected OVX rats exhibited LI whereas amphetamine-injected OVX rats did not exhibit LI. Administration of clozapine or $17 \beta$-estradiol alone failed to restore LI in amphetamine-injected OVX rats, but LI was restored in rats that were coadministered with clozapine and $17 \beta$-estradiol. On their own, clozapine and $17 \beta$-estradiol spared LI. ANOVA yielded significant main effects of pre-exposure $\left(\mathrm{F}_{(1,100)}=102.39, p<0.001\right)$, treatment $\left(\mathrm{F}_{(1,99)}=31.76, \quad p<0.001\right)$, and pretreatment 


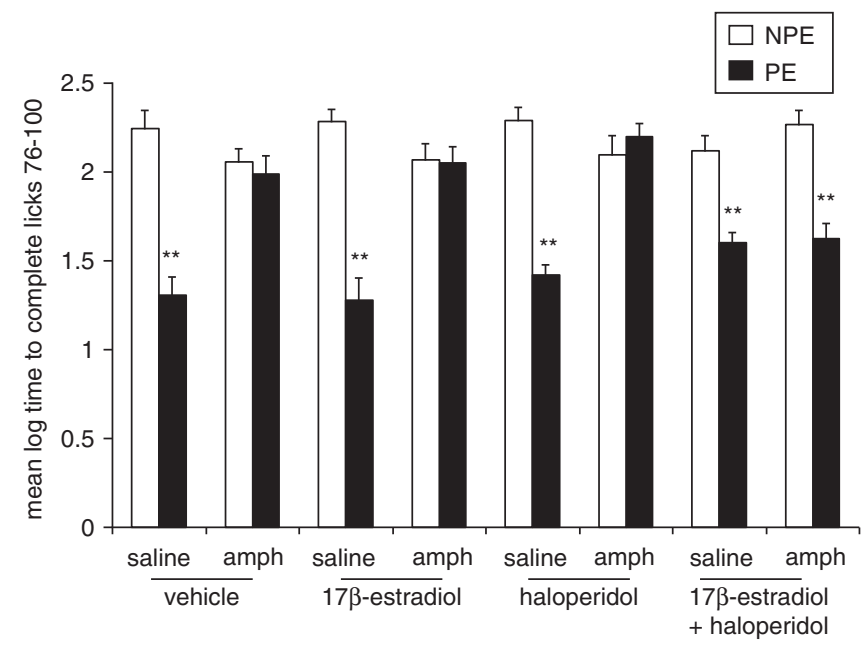

Figure 6 Effects of coadministration of haloperidol $(0.1 \mathrm{mg} / \mathrm{kg})$ and $17 \beta$ estradiol $(50 \mu \mathrm{g} / \mathrm{kg})$ on amphetamine-induced $\mathrm{LI}$ disruption in OVX rats. Mean ( \pm SEM) log times to complete licks 76-100 (after tone onset) of the pre-exposed (PE) and the non-pre-exposed (NPE) saline- or amphetamine (amph)-injected OVX rats administered with vehicle (vehicle), $50 \mu \mathrm{g} / \mathrm{kg}$ $17 \beta$-estradiol (I7 $\beta$-estradiol), $0.1 \mathrm{mg} / \mathrm{kg}$ haloperidol (haloperidol), or $17 \beta$-estradiol + haloperidol. Asterisks (**) indicate significant difference between the PE and NPE groups, namely, presence of $\mathrm{LI}(p<0.0 \mathrm{I})$.

$\left(\mathrm{F}_{(3,100)}=3.38, \quad p<0.05\right)$, as well as a significant preexposure $\times$ treatment $\times$ pretreatment interaction $\left(\mathrm{F}_{(3,100)}=\right.$ 6.21, $p<0.001)$. Post hoc comparisons confirmed the presence of LI in all four groups of saline-injected OVX rats, as well as in amphetamine-injected rats that received clozapine $+17 \beta$-estradiol ( $p$ 's $<0.01$ ), but not in the other conditions.

\section{DISCUSSION}

In this study, we showed that (1) amphetamine disrupted LI in OVX rats as it did in sham-operated controls; (2) compared to sham controls, reversal of amphetamineinduced LI disruption in OVX rats required higher doses of $17 \beta$-estradiol and clozapine and was resistant to haloperidol; (3) coadministration of low dose of clozapine and haloperidol with an ineffective dose of $17 \beta$-estradiol restored LI in amphetamine-injected OVX rats; and (4) $17 \beta$-estradiol at medium and high doses reversed amphetamine-induced LI disruption in sham rats.

Compared to our previous study centered on OVXinduced disruption of LI (Arad and Weiner, 2009), in this work the LI protocol has been changed so that OVX no longer disrupted LI and an effect of amphetamine could be shown. In experiment 1 , as in the work by Arad and Weiner (2009), no LI was evident in OVX rats if 40 pre-exposures were followed by 2 conditioning trials. However, raising the number of pre-exposures to 50 or reducing the number of conditioning trials to 1 led to emergence of LI in these rats. Nofrey et al (2008) have also found LI in OVX rats. The fact that OVX effects on LI can be influenced by changing procedural parameters indicates that hormonal level has no role in the acquisition of LI, but exerts a modulatory influence on its expression. Given the well-documented

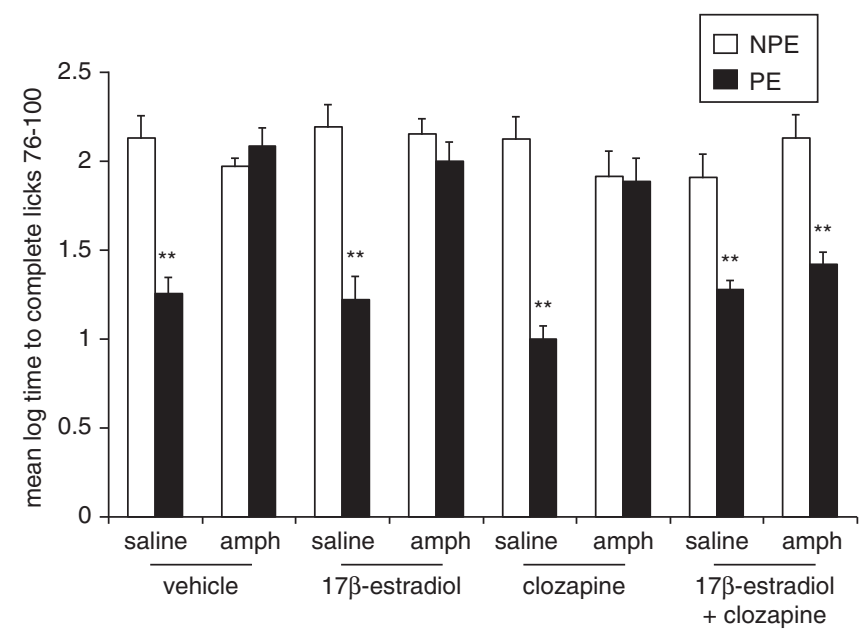

Figure 7 Effects of coadministration of clozapine $(5 \mathrm{mg} / \mathrm{kg})$ and $17 \beta$ estradiol $(50 \mu \mathrm{g} / \mathrm{kg})$ on amphetamine-induced $\mathrm{LI}$ disruption in OVX rats. Mean ( \pm SEM) log times to complete licks 76-100 (after tone onset) of the pre-exposed (PE) and the non-pre-exposed (NPE) saline- or amphetamine (amph)-injected OVX rats administered with vehicle (vehicle), $50 \mu \mathrm{g} / \mathrm{kg}$ ( $17 \beta$-estradiol), $5 \mathrm{mg} / \mathrm{kg}$ (clozapine), or $17 \beta$-estradiol + clozapine. Asterisks (**) indicate significant difference between the PE and NPE groups, namely, presence of $\mathrm{LI} p<0.0 \mathrm{I}$ ).

capacity of estrogen to modulate DA neurotransmission (Becker, 1999; Bourque et al, 2009; Chavez et al, 2010; Dluzen and Horstink, 2003; Hughes et al, 2009; Morissette et al, 2008), it is noteworthy that DA manipulations also exert only a modulatory influence on the expression of LI (Weiner, 2003).

Under conditions yielding LI in OVX rats, amphetamine disrupted LI as it did in sham controls. Disruption of LI reflects a selective attention deficit, whereby animals lose the capacity to ignore the irrelevant stimulus, and is also observed in amphetamine-treated humans, as well as in high-schizotypal humans (Braunstein-Bercovitz et al, 2002; Gray et al, 1992b; Salgado et al, 2000; Swerdlow et al, 2003; Thornton et al, 1996) and in acutely psychotic schizophrenia patients (Baruch et al, 1988; Gray et al, 1992a, 1995b; Rascle et al, 2001; but also see Swerdlow et al, 2005). A failure to inhibit attention to irrelevant stimuli is likely to give rise to aberrantly increased salience perception and distractibility that are associated with psychotic symptoms (Kapur et al, 2005; Weiner and Arad, 2009). These results show that unlike the reduced efficacy of APDs in OVX rats, the efficacy of amphetamine is not compromised by OVX. The latter suggests that the pro-psychotic action of amphetamine, and by extension, of increased dopaminergic function does not require estrogen. Similar results were reported with PPI. OVX spared PPI, which was disrupted by the DA agonist apomorphine (Gogos et al, 2009; Van den Buuse and Eikelis, 2001). PPI in OVX rats was disrupted also by the pro-psychotic NMDA antagonist MK-801. We have also found that MK-801 exerts the same effect on LI in OVX and sham rats ( $M$ Arad and I Weiner, unpublished data). Taken together, these results indicate that pro-psychotic drugs from different classes remain effective in OVX rats.

As shown repeatedly in the past using males (for review see Weiner, 2003; Weiner and Arad, 2009), amphetamine- 
induced LI disruption in sham female rats was reversed here by both clozapine and haloperidol, at both doses used. However, both drugs were less effective in OVX rats. Clozapine was effective only at the higher $10 \mathrm{mg} / \mathrm{kg}$ dose, and haloperidol failed to restore LI at both the 0.1 and $0.3 \mathrm{mg} / \mathrm{kg}$ doses. These outcomes extend our previous demonstration of reduced APD efficacy in reversing LI disruption in pharmacologically nontreated OVX rats (Arad and Weiner, 2009). Moreover, LI disruption in amphetamine-treated OVX rats is more resistant to APDs because in the previous study, clozapine was effective at the $5 \mathrm{mg} / \mathrm{kg}$ dose. These results support our previous conclusion that OVX-induced loss of estrogen reduces the potency of APDs, and further indicate that loss of estrogen coupled with hyperdopaminergia aggravates the loss of APDs efficacy so that not only typical but also atypical APDs, which are considered more effective antipsychotics in general (Horacek et al, 2006; Stone and Pilowsky, 2006) and in women in particular (de Leon et al, 2004), lose their efficacy.

Failure of APDs to restore disrupted LI, and in particular the different efficacies of haloperidol and clozapine, in OVX rats, are of particular interest given that in male rats, reversal by both classes of APDs has characterized to date all known instances of LI disruption, be they induced by pharmacological (Barak and Weiner, 2007; Russig et al, 2003), brain lesion (Coutureau et al, 1999; Weiner et al, 1996a), neurodevelopmental (Zuckerman et al, 2003), or parametric (Killcross et al, 1994b; Shadach et al, 1999; Weiner et al, 1996b) manipulations. Thus, loss of estrogen in female rats appears to exert a unique and powerful interference with APD action.

Following our previous demonstration that concurrent $17 \beta$-estradiol treatment potentiated the action of APDs (Arad and Weiner, 2009), here we postulated that ineffective APD doses would also regain their capacity to block amphetamine-induced disrupted LI in the presence of estrogen. Indeed we found that coadministration of low haloperidol and low clozapine doses with an ineffective dose of $17 \beta$-estradiol restored the efficacy of haloperidol and clozapine, although each of the drugs alone (in these doses) did not restore LI. These results indicate that $17 \beta$-estradiol restores specifically the anti-psychotic (anti-amphetamine) action of APDs, both typical and atypical. The latter outcome is consistent with other reports that the behavioral effects of D2 antagonists in OVX rats are potentiated by coadministration of $17 \beta$-estradiol (Bedard et al, 1982; Daniel, 2006; De Ryck et al, 1982; Di Paolo et al, 1979, 1984; Nicoletti et al, 1983; Palermo-Neto and Dorce, 1990).

$17 \beta$-Estradiol not only potentiated the anti-amphetamine action of APDs but also prevented amphetamine from disrupting LI when given on its own. Gogos et al (2009) recently found that chronic estradiol blocked disruption of PPI induced by apomorphine. Importantly, here $17 \beta$ estradiol blocked amphetamine effects in both OVX and sham rats. Furthermore, although the anti-amphetamine action was exerted in sham rats by both 50 and $150 \mu \mathrm{g} / \mathrm{kg}$ $17 \beta$-estradiol, in OVX rats only the highest dose of $150 \mu \mathrm{g} /$ $\mathrm{kg}$ exerted such action. The fact that a higher $17 \beta$-estradiol dose was needed to counteract amphetamine action in OVX rats suggests that low level of hormones and hyperdopaminergia are synergistic, supporting the notion that OVXinduced hormonal reduction is pro-psychotic.
The low dose of $17 \beta$-estradiol $(10 \mu \mathrm{g} / \mathrm{kg})$, although having no effect on amphetamine-induced disruption in both sham and OVX rats, disrupted LI in both sham and OVX rats. Nofrey et al (2008) have also reported that under conditions in which OVX spared LI, $10 \mu \mathrm{g} / \mathrm{kg}$ of $17 \beta$-estradiol disrupted LI. Taken together, results by Nofrey et al (2008) and by us suggest that high doses of estradiol exert an antipsychotic action whereas low doses exert a pro-psychotic action.

Amphetamine-induced LI disruption and its reversal by APDs are mediated by increased DA release and blockade of DA transmission, respectively, within the nucleus accumbens (Gray et al, 1995a; Warburton et al, 1996; Weiner, 2003). Consequently, our results imply that acute high dose of estradiol, which blocked the effects of amphetamine and potentiated the effects of haloperidol on LI, reduced mesolimbic DA function, whereas low dose, which disrupted LI, increased DA release within the nucleus accumbens. Results consistent with both reduction and increase of striatal dopaminergic function by estradiol have been reported for all indices of dopaminergic activity, including receptor levels/binding, membrane dopamine transporter levels, and release, depending on dose and treatment paradigm (Arvin et al, 2000; Bazzett and Becker, 1994; Becker and Beer, 1986; Becker and Rudick, 1999; Di Paolo, 1994, 1982, 1984, 1985; Disshon et al, 1998; Disshon and Dluzen, 2000; Dluzen, 1997; Landry et al, 2002; McDermott, 1993; McDermott et al, 1994; Morissette et al, 2008; Morissette and Di Paolo, 1993; Peris et al, 1991; Shieh and Yang, 2008; Thompson and Moss, 1994; Zhou et al, 2002). It has been suggested that antidopaminergic effects are primarily exerted by high doses of estrogen or chronic administration, whereas pro-dopaminergic actions are more associated with lower physiological levels of estrogen (Barber et al, 1976; Becker, 1999; Bedard et al, 1977; Cyr et al, 2002; Di Paolo, 1994; Di Paolo et al, 1981; Hruska and Silbergeld, 1980; McEwen and Alves, 1999; Riddoch et al, 1971). The specific mechanisms by which estradiol exerts the effects observed here remain to be elucidated.

OVX had been proposed to model gonadal hormone withdrawal occurring at menopause (Bosse and Di Paolo, 1995; Le Saux and Di Paolo, 2006; Vaillancourt et al, 2002). In support of this notion, we showed previously that OVX disrupts LI and impairs the efficacy of APDs to restore LI in OVX rats, in line with reduced APD efficacy reported in menopausal women with schizophrenia (Arad and Weiner, 2009). In this study, we used a combination of reduced hormonal level induced by OVX and increased dopaminergic activity induced by amphetamine to more closely model what may be occurring during menopause in women vulnerable to psychosis. Using disrupted LI and its restoration by $17 \beta$-estradiol and APDs as a behavioral readout for this biological constellation, our results have extended and strengthened our previous findings and their implications for the often-debated relationship between hormonal level and vulnerability to psychosis.

First, cessation of hormones interferes with the antipsychotic action of APDs as reflected in lowered efficacy to reverse amphetamine-induced LI disruption. Because the behavioral effects of amphetamine in general and amphetamine-induced LI disruption in particular are wellestablished models of psychosis, fortified by the capacity of amphetamine to induce and exacerbate psychosis in 
healthy and schizophrenic humans as well as enhance striatal DA release in schizophrenia patients (Laruelle et al, 1996, 1999), reduced efficacy of APDs in blocking amphetamine-induced behavioral abnormality allows a strong conclusion that loss of estrogen reduces specifically the antipsychotic potency of APDs. This reduced anti-amphetamine efficacy of APDs on the background of low hormonal level provides a close parallel to reduced efficacy of APD treatment in women with schizophrenia during periods associated with low levels of hormones (Kulkarni et al, 1996; Saugstad, 1989; Seeman, 1989; Seeman and Lang, 1990).

Second, cessation of hormones may be synergistic with hyperdopaminergia induced by amphetamine. Although our data do not show directly that amphetamine is more efficacious in disrupting LI in OVX rats, indirectly the data indicate that the effects of amphetamine on LI in OVX rats were more potent than in sham rats. Thus, a three times higher dose of $17 \beta$-estradiol was needed to block the LI disruptive effect of amphetamine in OVX than the dose needed in sham rats; in addition, both low and high doses of haloperidol and clozapine reversed disrupted LI in sham and OVX rats, but only high dose of clozapine was effective in OVX rats injected with amphetamine. It remains to be shown directly that OVX rats are more sensitive to LI disruptive effects of amphetamine. Such increased sensitivity could be shown by proving that amphetamine is effective in disrupting LI in OVX rats under conditions at which it loses capacity to disrupt LI in normal rats (De la Casa et al, 1993; Killcross et al, 1994a), or that LI disruption in OVX rats can be achieved by lower amphetamine doses than in control rats. However, be it normal or higher compared to sham, the potency of amphetamine in OVX rats sharply contrasts with the loss of potency of APDs after OVX. Reduced sensitivity to dopaminergic blockade coupled with intact/increased sensitivity to increased DA transmission in OVX rats may provide clues as to how loss of estrogen exacerbates or triggers psychosis in vulnerable women.

Finally, our results show that $17 \beta$-estradiol can exert antipsychotic activity as reflected in reversal of amphetamine-induced LI disruption in OVX and sham rats. As detailed in the Introduction, it has been suggested that exogenous estrogen may have antipsychotic properties or increase response to APDs in women with schizophrenia. Although the latter has been supported in several studies (Agius et al, 2009; Akhondzadeh et al, 2003; Cyr et al, 2002; Korhonen et al, 1995; Kulkarni, 2009; Kulkarni et al, 1996, 2001, 2008a,; Lindamer et al, 2001; Mortimer, 2007; Rao and Kolsch, 2003), other studies reported that estrogen treatment failed to improve or even worsened symptoms (Bergemann et al, 2005; Chua et al, 2005; Gattaz et al, 1994; Lindamer et al, 2001; for review see Mortimer, 2007). We previously provided support for antipsychotic capacity of $17 \beta$-estradiol by showing a synergistic effect of ineffective doses of $17 \beta$-estradiol and APDs in reversing OVX-induced disrupted LI (Arad and Weiner, 2009), and have replicated such a synergistic effect here for amphetamine-induced disrupted LI. However, although a synergistic action between APDs and $17 \beta$-estradiol implies that APDs require a certain level of estrogen to be effective, such dependence does not confer $17 \beta$-estradiol a direct antipsychotic action. In contrast, the capacity of $17 \beta$-estradiol given on its own to reverse amphetamine-induced disrupted LI in OVX rats as well as in sham rats strongly supports a direct antipsychotic action of $17 \beta$-estradiol. We have recently found that $17 \beta$ estradiol also reverses amphetamine-induced disrupted LI in male rats (M Arad and I Weiner, unpublished data).

In summary, the differential sensitivity to blockade and enhancement of dopaminergic transmission after OVX as seen here, with reduced sensitivity to DA blockade and spared or potentiated sensitivity to DA stimulation, may provide a novel model of menopausal psychosis that is associated with low levels of estrogen along with hyperfunction of the dopaminergic system. This constellation appears to rather accurately model the combination of increased vulnerability to psychosis with reduced response to APD treatment in female patients during menopause (Hafner, 2003; Seeman, 1989). Such a model may have important implications for the clinical progression and treatment of schizophrenia in women. Regarding the latter, our data are clear in showing that estrogen exerts antipsychotic activity. Unfortunately, in OVX rats and by extension in menopausal women, very high doses of $17 \beta$-estradiol would be needed. However, our data do suggest that using physiological $17 \beta$ estradiol doses as an add-on treatment may augment APD efficacy, and in fact may be more effective than raising the dose of APD.

A gender focus on mental disorders has been rapidly emerging in the last few years kindled by the acknowledgment of salient gender differences in all major psychiatric disorders. Much effort still needs to be invested by both clinical and basic research to study the biological and psychological causes and impacts of psychiatric disorders in the female gender. The present model is a step in this direction.

\section{DISCLOSURE}

The authors declare no conflict of interest.

\section{ACKNOWLEDGEMENTS}

We acknowledge the Joseph Sagol Fellowship Program in Humanities and Social Sciences at Tel-Aviv University for the funding (MA). We also acknowledge Novartis, Switzerland, for its generous gift of clozapine.

\section{REFERENCES}

Adam SK, Das S, Jaarin K (2009). A detailed microscopic study of the changes in the aorta of experimental model of postmenopausal rats fed with repeatedly heated palm oil. Int J Exp Pathol 90: 321-327.

Agius M, Hockings H, Wilson C, Lane D (2009). Is oestrogen neuroprotective? Psychiatr Danub 21(Suppl 1): 120-127.

Akhondzadeh S, Nejatisafa AA, Amini H, Mohammadi MR, Larijani B, Kashani L et al (2003). Adjunctive estrogen treatment in women with chronic schizophrenia: a double-blind, randomized, and placebo-controlled trial. Prog Neuropsychopharmacol Biol Psychiatry 27: 1007-1012.

Angermeyer MC, Kuhn L (1988). Gender differences in age at onset of schizophrenia. An overview. Eur Arch Psychiatry Neurol Sci 237: 351-364. 
Arad M, Weiner I (2008). Fluctuation of latent inhibition along the estrous cycle in the rat: modeling the cyclicity of symptoms in schizophrenic women? Psychoneuroendocrinology 33: 1401-1410.

Arad M, Weiner I (2009). Disruption of latent inhibition induced by ovariectomy can be reversed by estradiol and clozapine as well as by co-administration of haloperidol with estradiol but not by haloperidol alone. Psychopharmacology (Berl) 206: 731-740.

Arvin M, Fedorkova L, Disshon KA, Dluzen DE, Leipheimer RE (2000). Estrogen modulates responses of striatal dopamine neurons to $\mathrm{MPP}(+)$ : evaluations using in vitro and in vivo techniques. Brain Res 872: 160-171.

Barak S, Weiner I (2007). Scopolamine induces disruption of latent inhibition which is prevented by antipsychotic drugs and an acetylcholinesterase inhibitor. Neuropsychopharmacology 32: 989-999.

Barber PV, Arnold AG, Evans G (1976). Recurrent hormone dependent chorea: effects of oestrogens and progestogens. Clin Endocrinol (Oxf) 5: 291-293.

Barnes P, Staal V, Muir J, Good MA (2006). 17-Beta estradiol administration attenuates deficits in sustained and divided attention in young ovariectomized rats and aged acyclic female rats. Behav Neurosci 120: 1225-1234.

Baruch I, Hemsley DR, Gray JA (1988). Differential performance of acute and chronic schizophrenics in a latent inhibition task. J Nerv Ment Dis 176: 598-606.

Bazzett TJ, Becker JB (1994). Sex differences in the rapid and acute effects of estrogen on striatal D2 dopamine receptor binding. Brain Res 637: 163-172.

Becker JB (1999). Gender differences in dopaminergic function in striatum and nucleus accumbens. Pharmacol Biochem Behav 64: 803-812.

Becker JB, Beer ME (1986). The influence of estrogen on nigrostriatal dopamine activity: behavioral and neurochemical evidence for both pre- and postsynaptic components. Behav Brain Res 19: 27-33.

Becker JB, Rudick CN (1999). Rapid effects of estrogen or progesterone on the amphetamine-induced increase in striatal dopamine are enhanced by estrogen priming: a microdialysis study. Pharmacol Biochem Behav 64: 53-57.

Bedard P, Langelier P, Villeneuve A (1977). Oestrogens and extrapyramidal system. Lancet 2: 1367-1368.

Bedard PJ, Malouin F, Dipaolo T, Labrie F (1982). Estradiol, TRH and striatal dopaminergic mechanisms. Prog Neuropsychopharmacol Biol Psychiatry 6: 555-561.

Bergemann N, Mundt C, Parzer P, Pakrasi M, Eckstein-Mannsperger U, Haisch $S$ et al (2005). Estrogen as an adjuvant therapy to antipsychotics does not prevent relapse in women suffering from schizophrenia: results of a placebo-controlled double-blind study. Schizophr Res 74: 125-134.

Bosse R, Di Paolo T (1995). Dopamine and GABAA receptor imbalance after ovariectomy in rats: model of menopause. J Psychiatry Neurosci 20: 364-371.

Bourque M, Dluzen DE, Di Paolo T (2009). Neuroprotective actions of sex steroids in Parkinson's disease. Front Neuroendocrinol 30: 142-157.

Braunstein-Bercovitz H, Rammsayer T, Gibbons H, Lubow RE (2002). Latent inhibition deficits in high-schizotypal normals: symptom-specific or anxiety-related? Schizophr Res 53: $109-121$.

Chavez C, Hollaus M, Scarr E, Pavey G, Gogos A, van den Buuse M (2010). The effect of estrogen on dopamine and serotonin receptor and transporter levels in the brain: an autoradiography study. Brain Res (e-pub ahead of print)

Chua WL, de Izquierdo SA, Kulkarni J, Mortimer A (2005). Estrogen for schizophrenia. Cochrane Database Syst Rev 4 Art. No. CD004719.
Coutureau E, Galani R, Gosselin O, Majchrzak M, Di Scala G (1999). Entorhinal but not hippocampal or subicular lesions disrupt latent inhibition in rats. Neurobiol Learn Mem 72: 143-157.

Cyr M, Calon F, Morissette M, Di Paolo T (2002). Estrogenic modulation of brain activity: implications for schizophrenia and Parkinson's disease. J Psychiatry Neurosci 27: 12-27.

Daniel JM (2006). Effects of oestrogen on cognition: what have we learned from basic research? J Neuroendocrinol 18: 787-795.

Daniel JM, Hulst JL, Berbling JL (2006). Estradiol replacement enhances working memory in middle-aged rats when initiated immediately after ovariectomy but not after a long-term period of ovarian hormone deprivation. Endocrinology 147: 607-614.

De la Casa LG, Ruiz G, Lubow RE (1993). Amphetamine-produced attenuation of latent inhibition is modulated by stimulus preexposure duration: implications for schizophrenia. Biol Psychiatry 33: 707-711.

de Leon J, Diaz FJ, Josiassen RC, Simpson GM (2004). Possible individual and gender differences in the small increases in plasma prolactin levels seen during clozapine treatment. Eur Arch Psychiatry Clin Neurosci 254: 318-325.

De Ryck M, Hruska RE, Silbergeld EK (1982). Estrogen and haloperidol-induced versus handling-related catalepsy in male rats. Pharmacol Biochem Behav 17: 1027-1035.

Di Paolo T (1994). Modulation of brain dopamine transmission by sex steroids. Rev Neurosci 5: 27-41.

Di Paolo T, Carmichael R, Labrie F, Raynaud JP (1979). Effects of estrogens on the characteristics of $[3 \mathrm{H}]$ spiroperidol and [3H]RU24213 binding in rat anterior pituitary gland and brain. Mol Cell Endocrinol 16: 99-112.

Di Paolo T, Daigle M, Labrie F (1984). Effect of estradiol and haloperidol on hypophysectomized rat brain dopamine receptors. Psychoneuroendocrinology 9: 399-404.

Di Paolo T, Dupont A, Daigle M (1982). Effect of chronic estradiol treatment on dopamine concentrations in discrete brain nuclei of hypophysectomized female rats. Neurosci Lett 32: 295-300.

Di Paolo T, Poyet P, Labrie F (1981). Effect of chronic estradiol and haloperidol treatment on striatal dopamine receptors. Eur J Pharmacol 73: 105-106.

Di Paolo T, Rouillard C, Bedard P (1985). 17Beta-estradiol at a physiological dose acutely increases dopamine turnover in rat brain. Eur J Pharmacol 117: 197-203.

Disshon KA, Boja JW, Dluzen DE (1998). Inhibition of striatal dopamine transporter activity by 17beta-estradiol. Eur J Pharmacol 345: 207-211.

Disshon KA, Dluzen DE (2000). Estrogen reduces acute striatal dopamine responses in vivo to the neurotoxin $\mathrm{MPP}+$ in female, but not male rats. Brain Res 868: 95-104.

Dluzen D (1997). Estrogen decreases corpus striatal neurotoxicity in response to 6-hydroxydopamine. Brain Res 767: 340-344.

Dluzen D, Horstink M (2003). Estrogen as neuroprotectant of nigrostriatal dopaminergic system: laboratory and clinical studies. Endocrine 21: 67-75.

Earley CJ, Leonard BE (1978). Behavioural studies on the effects of $\mathrm{d}$-amphetamine and estradiol benzoate alone and in combination. Psychopharmacology (Berl) 56: 179-183.

Ereshefsky L, Saklad SR, Watanabe MD, Davis CM, Jann MW (1991). Thiothixene pharmacokinetic interactions: a study of hepatic enzyme inducers, clearance inhibitors, and demographic variables. J Clin Psychopharmacol 11: 296-301.

Farina G, Moretti G, Crivelli G (1981). [Psychopathology and clinical picture of symbiotic psychoses]. Minerva Psichiatr 22: 215-225.

Frye CA (2001). The role of neurosteroids and non-genomic effects of progestins and androgens in mediating sexual receptivity of rodents. Brain Res Brain Res Rev 37: 201-222.

Frye CA, Duffy CK, Walf AA (2007). Estrogens and progestins enhance spatial learning of intact and ovariectomized 
rats in the object placement task. Neurobiol Learn Mem 88: 208-216.

Frye CA, Rhodes ME (2006a). Infusions of 5alpha-pregnan-3alphaol-20-one (3alpha,5alpha-THP) to the ventral tegmental area, but not the substantia nigra, enhance exploratory, anti-anxiety, social and sexual behaviours and concomitantly increase 3alpha,5alpha-THP concentrations in the hippocampus, diencephalon and cortex of ovariectomised oestrogen-primed rats. J Neuroendocrinol 18: 960-975.

Frye CA, Rhodes ME, Petralia SM, Walf AA, Sumida K, Edinger KL (2006b). 3Alpha-hydroxy-5alpha-pregnan-20-one in the midbrain ventral tegmental area mediates social, sexual, and affective behaviors. Neuroscience 138: 1007-1014.

Galea LA, Wide JK, Barr AM (2001). Estradiol alleviates depressive-like symptoms in a novel animal model of postpartum depression. Behav Brain Res 122: 1-9.

Gattaz WF, Vogel P, Riecher-Rossler A, Soddu G (1994). Influence of the menstrual cycle phase on the therapeutic response in schizophrenia. Biol Psychiatry 36: 137-139.

Gibbs RB, Burke AM, Johnson DA (1998). Estrogen replacement attenuates effects of scopolamine and lorazepam on memory acquisition and retention. Horm Behav 34: 112-125.

Gogos A, Kwek P, Chavez CA, van den Buuse M (2009). Estrogen treatment blocks 8-OH-DPAT- and apomorphine-induced disruptions of prepulse inhibition: involvement of dopamine D1 or D2, serotonin 5-HT1A, 5-HT2A or 5-HT7 receptors. J Pharmacol Exp Ther (e-pub ahead of print)

Gogos A, Van den Buuse M (2004). Estrogen and progesterone prevent disruption of prepulse inhibition by the serotonin-1A receptor agonist 8-hydroxy-2-dipropylaminotetralin. J Pharmacol Exp Ther 309: 267-274.

Gray JA, Joseph MH, Hemsley DR, Young AM, Warburton EC, Boulenguez P et al (1995a). The role of mesolimbic dopaminergic and retrohippocampal afferents to the nucleus accumbens in latent inhibition: implications for schizophrenia. Behav Brain Res 71: 19-31.

Gray NS, Hemsley DR, Gray JA (1992a). Abolition of latent inhibition in acute, but not chronic, schizophrenics. Neurol Psychiatry Brain Res 1: 83-89.

Gray NS, Pickering AD, Hemsley DR, Dawling S, Gray JA (1992b). Abolition of latent inhibition by a single $5 \mathrm{mg}$ dose of d-amphetamine in man. Psychopharmacology (Berl) 107: 425-430.

Gray NS, Pilowsky LS, Gray JA, Kerwin RW (1995b). Latent inhibition in drug naive schizophrenics: relationship to duration of illness and dopamine D2 binding using SPET. Schizophr Res 17: 95-107.

Gurkan L, Ekeland A, Gautvik KM, Langeland N, Ronningen H, Solheim LF (1986). Bone changes after castration in rats. A model for osteoporosis. Acta Orthop Scand 57: 67-70.

Hafner H (2003). Gender differences in schizophrenia. Psychoneuroendocrinology 28(Suppl 2): 17-54.

Hafner H, Riecher A, Maurer K, Loffler W, Munk-Jorgensen P, Stromgren E (1989). How does gender influence age at first hospitalization for schizophrenia? A transnational case register study. Psychol Med 19: 903-918.

Horacek J, Bubenikova-Valesova V, Kopecek M, Palenicek T, Dockery C, Mohr P et al (2006). Mechanism of action of atypical antipsychotic drugs and the neurobiology of schizophrenia. CNS Drugs 20: 389-409.

Hruska RE, Silbergeld EK (1980). Increased dopamine receptor sensitivity after estrogen treatment using the rat rotation model. Science 208: 1466-1468.

Huber TJ, Borsutzky M, Schneider U, Emrich HM (2004). Psychotic disorders and gonadal function: evidence supporting the oestrogen hypothesis. Acta Psychiatr Scand 109: 269-274.

Hughes ZA, Liu F, Marquis K, Muniz L, Pangalos MN, Ring RH et al (2009). Estrogen receptor neurobiology and its potential for translation into broad spectrum therapeutics for CNS disorders. Curr Mol Pharmacol 2: 215-236.

Iacono WG, Beiser M (1992). Where are the women in first-episode studies of schizophrenia? Schizophr Bull 18: 471-480.

Kapur S, Mizrahi R, Li M (2005). From dopamine to salience to psychosis - linking biology, pharmacology and phenomenology of psychosis. Schizophr Res 79: 59-68.

Killcross AS, Dickinson A, Robbins TW (1994a). Amphetamineinduced disruptions of latent inhibition are reinforcer mediated: implications for animal models of schizophrenic attentional dysfunction. Psychopharmacology (Berl) 115: 185-195.

Killcross AS, Dickinson A, Robbins TW (1994b). Effects of the neuroleptic alpha-flupenthixol on latent inhibition in aversively- and appetitively-motivated paradigms: evidence for dopamine-reinforcer interactions. Psychopharmacology (Berl) 115: 196-205.

Koch M (1998). Sensorimotor gating changes across the estrous cycle in female rats. Physiol Behav 64: 625-628.

Korhonen S, Saarijarvi S, Aito M (1995). Successful estradiol treatment of psychotic symptoms in the premenstrual phase: a case report. Acta Psychiatr Scand 92: 237-238.

Kraepeline E (1919). Dementia Praecox and Paraphrenia. Krieger: New York, NY.

Kulkarni J (2009). Oestrogen - a new treatment approach for schizophrenia? Med J Aust 190(4 Suppl): S37-S38.

Kulkarni J, de Castella A, Fitzgerald PB, Gurvich CT, Bailey M, Bartholomeusz C et al (2008a). Estrogen in severe mental illness: a potential new treatment approach. Arch Gen Psychiatry 65: 955-960.

Kulkarni J, de Castella A, Smith D, Taffe J, Keks N, Copolov D (1996). A clinical trial of the effects of estrogen in acutely psychotic women. Schizophr Res 20: 247-252.

Kulkarni J, Gurvich C, Gilbert H, Mehmedbegovic F, Mu L, Marston $\mathrm{N}$ et al (2008b). Hormone modulation: a novel therapeutic approach for women with severe mental illness. Aust N Z J Psychiatry 42: 83-88.

Kulkarni J, Riedel A, de Castella AR, Fitzgerald PB, Rolfe TJ, Taffe J et al (2001). Estrogen - a potential treatment for schizophrenia. Schizophr Res 48: 137-144.

Landry M, Levesque D, Di Paolo T (2002). Estrogenic properties of raloxifene, but not tamoxifen, on D2 and D3 dopamine receptors in the rat forebrain. Neuroendocrinology 76: 214-222.

Lane HY, Chang YC, Chang WH, Lin SK, Tseng YT, Jann MW (1999). Effects of gender and age on plasma levels of clozapine and its metabolites: analyzed by critical statistics. J Clin Psychiatry 60: 36-40.

Laruelle M, Abi-Dargham A, Gil R, Kegeles L, Innis R (1999). Increased dopamine transmission in schizophrenia: relationship to illness phases. Biol Psychiatry 46: 56-72.

Laruelle M, Abi-Dargham A, van Dyck CH, Gil R, D'Souza CD, Erdos $J$ et al (1996). Single photon emission computerized tomography imaging of amphetamine-induced dopamine release in drug-free schizophrenic subjects. Proc Natl Acad Sci USA 93: 9235-9240.

Le Saux M, Di Paolo T (2006). Influence of oestrogenic compounds on monoamine transporters in rat striatum. J Neuroendocrinol 18: $25-32$.

LeBlanc AJ, Reyes R, Kang LS, Dailey RA, Stallone JN, Moningka NC et al (2009). Estrogen replacement restores flowinduced vasodilation in coronary arterioles of aged and ovariectomized rats. Am J Physiol Regul Integr Comp Physiol 297: R1713-R1723.

Lindamer LA, Buse DC, Lohr JB, Jeste DV (2001). Hormone replacement therapy in postmenopausal women with schizophrenia: positive effect on negative symptoms? Biol Psychiatry 49: 47-51.

Lindamer LA, Lohr JB, Harris MJ, Jeste DV (1997). Gender, estrogen, and schizophrenia. Psychopharmacol Bull 33: 221-228. 
Lipska BK, Weinberger DR (2002). A neurodevelopmental model of schizophrenia: neonatal disconnection of the hippocampus. Neurotox Res 4: 469-475.

Marcondes FK, Bianchi FJ, Tanno AP (2002). Determination of the estrous cycle phases of rats: some helpful considerations. Braz J Biol 62(4A): 609-614.

McDermott JL (1993). Effects of estrogen upon dopamine release from the corpus striatum of young and aged female rats. Brain Res 606: 118-125.

McDermott JL, Liu B, Dluzen DE (1994). Sex differences and effects of estrogen on dopamine and DOPAC release from the striatum of male and female CD-1 mice. Exp Neurol 125: 306-311.

McEwen BS, Alves SE (1999). Estrogen actions in the central nervous system. Endocr Rev 20: 279-307.

Morissette M, Al Sweidi S, Callier S, Di Paolo T (2008). Estrogen and SERM neuroprotection in animal models of Parkinson's disease. Mol Cell Endocrinol 290: 60-69.

Morissette M, Di Paolo T (1993). Effect of chronic estradiol and progesterone treatments of ovariectomized rats on brain dopamine uptake sites. J Neurochem 60: 1876-1883.

Mortimer AM (2007). Relationship between estrogen and schizophrenia. Expert Rev Neurother 7: 45-55.

Moser PC, Hitchcock JM, Lister S, Moran PM (2000). The pharmacology of latent inhibition as an animal model of schizophrenia. Brain Res Brain Res Rev 33: 275-307.

Naik SR, Kelkar MR, Sheth UK (1978). Attenuation of stereotyped behaviour by sex steroids. Psychopharmacology (Berl) 57: 211-214.

Nequin LG, Alvarez J, Schwartz NB (1979). Measurement of serum steroid and gonadotropin levels and uterine and ovarian variables throughout 4 day and 5 day estrous cycles in the rat. Biol Reprod 20: 659-670.

Nicoletti F, Ferrara N, Patti F, Viglianesi M, Rampello L, Bianchi A et al (1983). Influence of sex steroids and prolactin on haloperidol-induced catalepsy. Brain Res 279: 352-358.

Nofrey BS, Ben-Shahar OM, Brake WG (2008). Estrogen abolishes latent inhibition in ovariectomized female rats. Brain Cogn 66: 156-160.

Palermo-Neto J, Dorce VA (1990). Influences of estrogen and/or progesterone on some dopamine related behavior in rats. Gen Pharmacol 21: 83-87.

Paris JJ, Frye CA (2008). Estrous cycle, pregnancy, and parity enhance performance of rats in object recognition or object placement tasks. Reproduction 136: 105-115.

Peris J, Decambre N, Coleman-Hardee ML, Simpkins JW (1991). Estradiol enhances behavioral sensitization to cocaine and amphetamine-stimulated striatal $[3 \mathrm{H}]$ dopamine release. Brain Res 566: 255-264.

Pregelj P (2009). Neurobiological aspects of psychosis and gender. Psychiatr Danub 21(Suppl 1): 128-131.

Rao ML, Kolsch H (2003). Effects of estrogen on brain development and neuroprotection-implications for negative symptoms in schizophrenia. Psychoneuroendocrinology 28(Suppl 2): 83-96.

Rascle C, Mazas O, Vaiva G, Tournant M, Raybois O, Goudemand $M$ et al (2001). Clinical features of latent inhibition in schizophrenia. Schizophr Res 51: 149-161.

Riddoch D, Jefferson M, Bickerstaff ER (1971). Chorea and the oral contraceptives. Br Med J 4: 217-218.

Riecher-Rossler A, Hafner H (2000). Gender aspects in schizophrenia: bridging the border between social and biological psychiatry. Acta Psychiatr Scand Suppl 407: 58-62.

Rogers NH, Perfield 2nd JW, Strissel KJ, Obin MS, Greenberg AS (2009). Reduced energy expenditure and increased inflammation are early events in the development of ovariectomy-induced obesity. Endocrinology 150: 2161-2168.

Russig H, Kovacevic A, Murphy CA, Feldon J (2003). Haloperidol and clozapine antagonise amphetamine-induced disruption of latent inhibition of conditioned taste aversion. Psychopharmacology (Berl) 170: 263-270.
Salem JE, Kring AM (1998). The role of gender differences in the reduction of etiologic heterogeneity in schizophrenia. Clin Psychol Rev 18: 795-819.

Salgado JV, Hetem LA, Vidal M, Graeff FG, Danion JM, Sandner G (2000). Reduction of latent inhibition by D-amphetamine in a conditioned suppression paradigm in humans. Behav Brain Res 117: 61-67.

Salokangas RK (1995). Gender and the use of neuroleptics in schizophrenia. Further testing of the oestrogen hypothesis. Schizophr Res 16: 7-16.

Saugstad LF (1989). Social class, marriage, and fertility in schizophrenia. Schizophr Bull 15: 9-43.

Seeman MV (1982). Gender differences in schizophrenia. Can J Psychiatry 27: 107-112.

Seeman MV (1986). Current outcome in schizophrenia: women vs men. Acta Psychiatr Scand 73: 609-617.

Seeman MV (1989). Prenatal gonadal hormones and schizophrenia in men and women. Psychiatr J Univ Ott 14: 473-475.

Seeman MV, Lang M (1990). The role of estrogens in schizophrenia gender differences. Schizophr Bull 16: 185-194.

Segarra AC, Agosto-Rivera JL, Febo M, Lugo-Escobar N, MenéndezDelmestre R, Puig-Ramos A et al (2009). Estradiol: a key biological substrate mediating the response to cocaine in female rats. Horm Behav doi:10.1016/j.yhbeh.2009.12.003 (e-pub ahead of print)

Shadach E, Feldon J, Weiner I (1999). Clozapine-induced potentiation of latent inhibition is due to its action in the conditioning stage: implications for the mechanism of action of antipsychotic drugs. Int J Neuropsychopharmacol 2: 283-291.

Shaikh AA (1971). Estrone and estradiol levels in the ovarian venous blood from rats during the estrous cycle and pregnancy. Biol Reprod 5: 297-307.

Shieh KR, Yang SC (2008). Effects of estradiol on the stimulation of dopamine turnover in mesolimbic and nigrostriatal systems by cocaine- and amphetamine-regulated transcript peptide in female rats. Neuroscience 154: 1589-1597.

Simpson GM, Yadalam KG, Levinson DF, Stephanos MJ, Lo ES, Cooper TB (1990). Single-dose pharmacokinetics of fluphenazine after fluphenazine decanoate administration. $J$ Clin Psychopharmacol 10: 417-421.

Stone JM, Pilowsky LS (2006). Antipsychotic drug action: targets for drug discovery with neurochemical imaging. Expert Rev Neurother 6: 57-64.

Swerdlow NR, Stephany N, Wasserman LC, Talledo J, Sharp R, Auerbach PP (2003). Dopamine agonists disrupt visual latent inhibition in normal males using a within-subject paradigm. Psychopharmacology (Berl) 169: 314-320.

Swerdlow NR, Stephany N, Wasserman LC, Talledo J, Sharp R, Minassian A et al (2005). Intact visual latent inhibition in schizophrenia patients in a within-subject paradigm. Schizophr Res 72: 169-183.

Szymanski S, Lieberman JA, Alvir JM, Mayerhoff D, Loebel A, Geisler S et al (1995). Gender differences in onset of illness, treatment response, course, and biologic indexes in first-episode schizophrenic patients. Am J Psychiatry 152: 698-703.

Tamminga CA (1997). Gender and schizophrenia. J Clin Psychiatry 58(Suppl 15): 33-37.

Thompson TL, Moss RL (1994). Estrogen regulation of dopamine release in the nucleus accumbens: genomic- and nongenomicmediated effects. J Neurochem 62: 1750-1756.

Thornton JC, Dawe S, Lee C, Capstick C, Corr PJ, Cotter P et al (1996). Effects of nicotine and amphetamine on latent inhibition in human subjects. Psychopharmacology (Berl) 127: 164-173.

Vaillancourt C, Cyr M, Rochford J, Boksa P, Di Paolo T (2002). Effects of ovariectomy and estradiol on acoustic startle responses in rats. Pharmacol Biochem Behav 74: 103-109.

Van den Buuse M, Eikelis N (2001). Estrogen increases prepulse inhibition of acoustic startle in rats. Eur J Pharmacol 425: 33-41. 
Walf AA, Frye CA (2010). Estradiol reduces anxiety- and depression-like behavior of aged female mice. Physiol Behav 99: 169-174.

Walf AA, Paris JJ, Frye CA (2009). Chronic estradiol replacement to aged female rats reduces anxiety-like and depression-like behavior and enhances cognitive performance. Psychoneuroendocrinology 34: 909-916.

Warburton EC, Mitchell SN, Joseph MH (1996). Calcium dependence of sensitised dopamine release in rat nucleus accumbens following amphetamine challenge: implications for the disruption of latent inhibition. Behav Pharmacol 7: 119-129.

Weiner I (1990). Neural substrates of latent inhibition: the switching model. Psychol Bull 108: 442-461.

Weiner I (2003). The 'two-headed' latent inhibition model of schizophrenia: modeling positive and negative symptoms and their treatment. Psychopharmacology (Berl) 169: 257-297.

Weiner I, Arad M (2009). Using the pharmacology of latent inhibition to model domains of pathology in schizophrenia and their treatment. Behav Brain Res 204: 369-386.

Weiner I, Feldon J (1987). Facilitation of latent inhibition by haloperidol in rats. Psychopharmacology (Berl) 91: 248-253.
Weiner I, Gal G, Rawlins JN, Feldon J (1996a). Differential involvement of the shell and core subterritories of the nucleus accumbens in latent inhibition and amphetamine-induced activity. Behav Brain Res 81: 123-133.

Weiner I, Shadach E, Barkai R, Feldon J (1997). Haloperidol- and clozapine-induced enhancement of latent inhibition with extended conditioning: implications for the mechanism of action of neuroleptic drugs. Neuropsychopharmacology 16: 42-50.

Weiner I, Shadach E, Tarrasch R, Kidron R, Feldon J (1996b). The latent inhibition model of schizophrenia: further validation using the atypical neuroleptic, clozapine. Biol Psychiatry 40: 834-843.

Zhou W, Cunningham KA, Thomas ML (2002). Estrogen regulation of gene expression in the brain: a possible mechanism altering the response to psychostimulants in female rats. Brain Res Mol Brain Res 100: 75-83.

Zuckerman L, Rehavi M, Nachman R, Weiner I (2003). Immune activation during pregnancy in rats leads to a postpubertal emergence of disrupted latent inhibition, dopaminergic hyperfunction, and altered limbic morphology in the offspring: a novel neurodevelopmental model of schizophrenia. Neuropsychopharmacology 28: 1778-1789. 